\title{
Improved gfp and inaZ Broad-Host-Range Promoter-Probe Vectors
}

\author{
William G. Miller, Johan H. J. Leveau, and Steven E. Lindow \\ University of California, Department of Plant and Microbial Biology, 111 Koshland Hall, Berkeley 94720, U.S.A. \\ Accepted 20 July 2000.
}

\begin{abstract}
A new set of broad-host-range promoter-probe vectors has been constructed. One subset contains the pVS1 and p15a replicons and confers resistance to either gentamicin or kanamycin. The other set contains the broad-host-range replicon from $\mathrm{pBBR} 1$ and confers resistance to kanamycin, tetracycline, ampicillin, or spectinomycin/streptomycin. Both plasmid sets are highly stable and are maintained without selection for more than 30 generations in several bacterial taxa. Each plasmid contains a promoter-probe cassette that consists of a multicloning site, containing several unique restriction sites, and $g f p$ or $i n a Z$ as a reporter gene. The cassette is bound by transcriptional terminators to permit the insertion of strong promoters and to insulate the cassette from external transcription enabling the detection of weak or moderate promoters. The vector suite was augmented with derivatives of the kanamycinresistant $g f p$ promoter-probe plasmids that encode Gfp variants with different half-life times.
\end{abstract}

Additional keywords: fluorescence, gene expression, ice nucleation, transcriptional fusion.

Transcriptional fusions are important tools in understanding gene expression and gene regulation. The construction of such fusions is greatly facilitated by the use of promoter-probe vectors. These vectors have a common motif in which a promoterless reporter gene, encoding an easily assayable protein, is present downstream of one or more restriction sites. Known promoter sequences or uncharacterized segments of genomic DNA can be ligated into these restriction sites, and the expression of the reporter gene can then be quantified under various conditions. In order to be of the greatest use, promoter-probe vectors should (i) be functional in as many taxa as possible, (ii) show a high degree of sensitivity to detect promoters that

Corresponding author: S. Lindow; Telephone: +1-510-642-4174; Fax: +1-510-642-4995; E-mail: icelab@ socrates.berkeley.edu

Current address of W. G. Miller: United States Department of Agriculture-Agricultural Research Service, Food Safety and Health Research Unit, 800 Buchanan St., Albany, CA 94710, U.S.A.

Nucleotide sequence data and accession numbers have been deposited in GenBank as follows: pPROBE-NT, AF286453; pPROBE-NT', AF286454; pPROBE-NI, AF286451; pPROBE-NI', AF286452; pPROBE-gfp[tagless], AF286455; pPROBE'-g $f$ [tagless], AF286456; pPROBE-g $f p$ [LVA], AF286461; pPROBE'-gfp [LVA], AF286462; pPROBE- $g f p[\mathrm{AAV}], \mathrm{AF} 286457$; pPROBE'$g f p[\mathrm{AAV}], \mathrm{AF} 286458 ;$ pPROBE- $g f p[\mathrm{ASV}], \mathrm{AF} 286459$; and pPROBE'$g f p[\mathrm{ASV}], \mathrm{AF} 286460$. are of weak to moderate strength, and (iii) be stable enough to be used in vivo without antibiotic selection.

Most of the early promoter-probe vectors that were constructed used the lac $Z$ reporter gene and contained either the ColE1 or p15a origin of replication (Casadaban and Cohen 1980; Silhavy and Beckwith 1985; Simons et al. 1987). These vectors, while suitable for use in Escherichia coli, either could not be maintained in many other taxa or would not be appropriate in organisms or hosts with native $\beta$-galactosidase activity. The ability to construct transcriptional fusions in organisms other than $E$. coli is increasingly important; therefore, in order for promoter-probe vectors to be more versatile, they need to contain broad-host-range origins of replication. Several such vectors have been described (Diaz and Garcia 1990; Konyecsni and Deretic 1988; Ronald et al. 1990). Additionally, many organisms are naturally resistant to varying levels of one or more antibiotics (Nikaido and Vaara 1995). Therefore, a set of promoter-probe vectors should also contain a wide variety of antibiotic resistance genes.

Quantification of weak to moderate transcriptional signals in many promoter-probe plasmids is often confounded by transcription that originates upstream of the promoter fusion. This high background level of reporter gene expression eliminates a large subset of promoters from detection by these plasmids. Some promoter-probe vectors have been described in which interference by read-through transcription is largely reduced by the addition of one or more transcriptional terminators upstream of the multicloning site (MCS) (Simons et al. 1987). Although elimination of upstream transcription increases the overall sensitivity of the vector, it is also important to consider the sensitivity of the reporter gene. The level of expression of some reporter genes that have been fused to weakly transcribed promoters may fall below the level of detectability. Some reporter genes, such as inaZ, which encodes a bacterial ice nucleation protein, are substantially more sensitive than lacZ or gfp (W. G. Miller, M. T. Brandl, B. Quiñones, and S. E. Lindow, unpublished data). The sensitivity of the reporter gene is also an important consideration when a low-copy-number plasmid, such as a broad-host-range vector, is used.

In this paper, we describe the construction of a set of promoter-probe vectors that combines all of the important features listed above. These promoter-probe vectors contain a common cassette, bound by one or more transcriptional terminators, that consists of an MCS upstream of a promoterless $g f p$ or inaZ reporter gene. In addition, this set of vectors contains two different broad-host-range origins of replication and 
five antibiotic resistance genes and is readily maintained in several different taxa without antibiotic selection.

\section{RESULTS AND DISCUSSION}

Construction of the promoter-probe vectors.

We constructed six sets of promoter-probe plasmids. Two sets contain the pVS1 and p15a replicons, and four sets contain the broad-host-range replicon from pBBR1 (Antoine and Locht 1992) (Fig. 1; Table 1). All members of each set share a common plasmid backbone but contain one of four different promoter-probe cassettes. Two cassettes in each set use $g f p$, which encodes green fluorescent protein, as the reporter; the other two use the inaZ ice nucleation gene. Additionally, in each reporter gene pair, the order of restriction enzymes in the polylinker is either HindIII to EcoRI (e.g., pPROBE-GT) or EcoRI to HindIII (e.g., pPROBE-GT').

The first step in the design of the promoter-probe vectors was the construction of a set of reporter gene cassettes. Basically, these cassettes consist of a reporter gene downstream of an MCS, flanked by strong transcriptional terminators and bound on both ends by NotI restriction sites. Four different
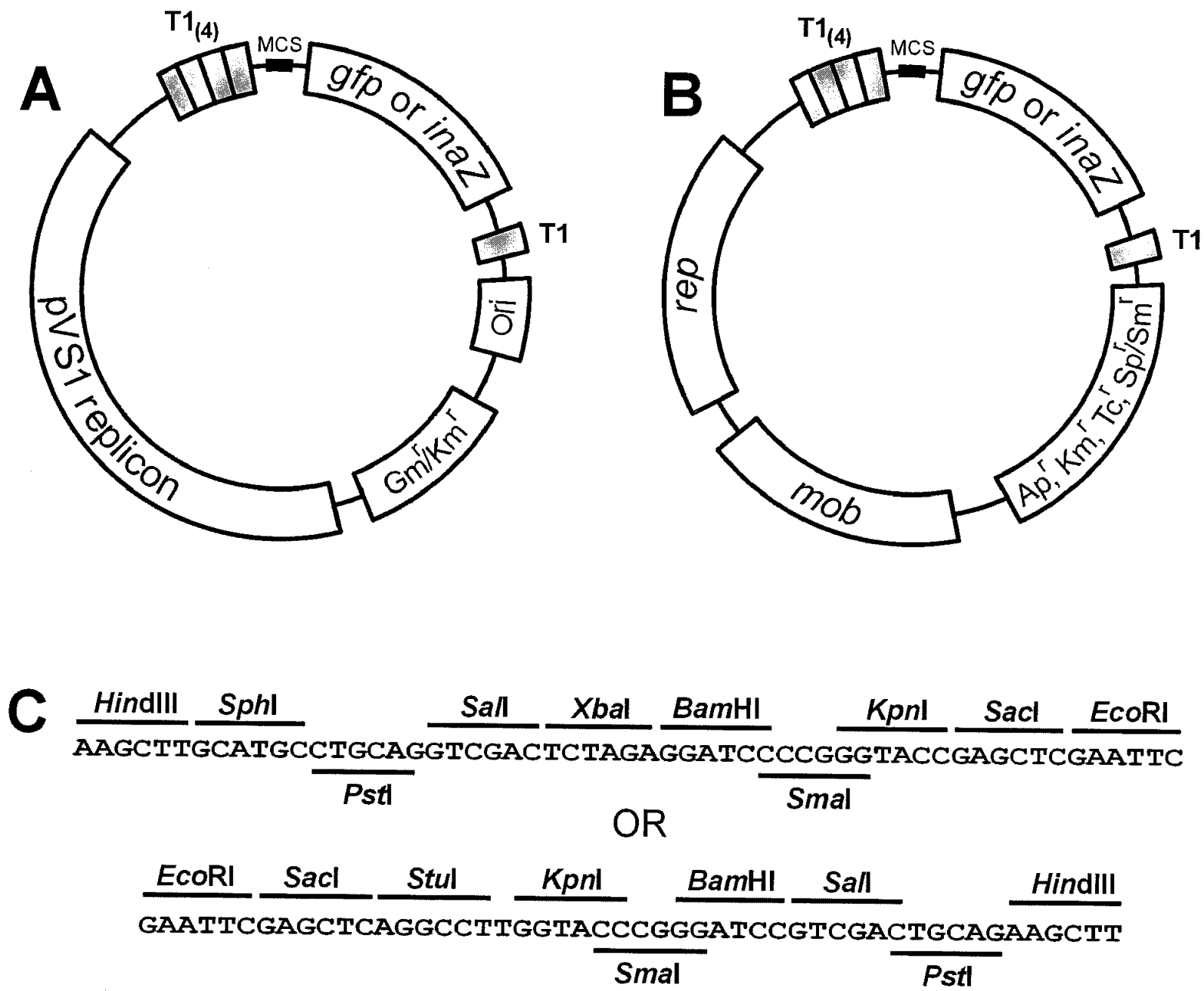

Fig. 1. Promoter-probe vectors. A, The pVS1/p15a-derived plasmids. These plasmids contain a region from pVS1 (indicated by 'pVS1 replicon') that contains the broad-host-range oriV origin of replication and the sta segment for segregation stability (Heeb et al. 2000; van der Bij et al. 1996). In addition, these plasmids contain the ori region of pACYC184 ('ori') that encompasses both the p15a origin of transfer, allowing pRK2013- or pRK2073mediated mobilization of these vectors, and the p15a origin of replication for maintenance in Escherichia coli. They also contain the gentamicin resistance gene (aacC1) from Tn1696 (Hirsch et al. 1986) or the kanamycin resistance gene (nptII) from Tn5. B, The pBBR1-derived plasmids. Based on plasmid pBBR1 from Bordetella bronchiseptica, these plasmids harbor genes required for replication (rep) and mobilization (mob) (Antoine and Locht 1992). Like the pVS1-p15a derivatives, these vectors are also mobilizable by conjugation using helper plasmid pRK2013 or pRK2073. These plasmids also contain one of four antibiotic resistance genes: the ampicillin resistance gene (bla) from pBR322, the kanamycin resistance gene from TnphoA (Manoil and Beckwith 1985), the tetracycline resistance gene from pWTT2081, or the omega fragment (Prentki and Krisch 1984) which contains the gene encoding resistance to both spectinomycin and streptomycin. Both types of promoter-probe vectors (A and $\mathbf{B}$ ) contain a common cassette that has (i) four tandem copies of the $\mathrm{T} 1$ terminator $\left(\mathrm{T} 1_{(4)}\right.$; shaded boxes) from the E. coli rrnB1 operon (Brosius et al. 1981), (ii) a multicloning site (solid box) containing either C, (top) the pUC18 polylinker (HindIII $\rightarrow$ EcoRI) or C, (bottom) a modified pUC19 polylinker (EcoRI $\rightarrow$ HindIII), in which the SphI and $\mathrm{XbaI}$ sites have been deleted and a StuI site inserted, (iii) the $g f p$ or inaZ reporter genes (including optimally placed ribosome binding sites: a synthetic one for $g f p$ [Miller and Lindow 1997] and the native one for inaZ), and (iv) a single $r r n B$ T1 terminator (T1; shaded box). In the pPROBE-GT, -GT', -GI, or -GI' vectors, the NotI sites are still present at each end of the cassette; they have been disrupted in the other promoter-probe vectors. 
cassettes were constructed: two of the cassettes contain the $g f p$ reporter gene and the other two, the inaZ gene. In addition, two of the cassettes contained, as the MCS, the pUC18 polylinker region. The MCS in the other two cassettes was constructed by replacing the pUC18 polylinker with a linker in which the restriction sites were arranged in reverse order, the $S p h \mathrm{I}$ and $X b a \mathrm{I}$ sites were removed, and an additional site for a blunt-end restriction enzyme, StuI, was inserted. This allows for the construction of fusions in which fragments with differently restricted ends can be ligated in either orientation.

The transcriptional terminator that we chose was the T1 terminator from the E. coli rrnBl operon (Brosius et al. 1981). This terminator, when placed upstream of the MCS, reduces the background level of expression caused by external transcription (Simons et al. 1987). One copy of the terminator can reduce background expression by $94 \%$; four tandem copies lower the background an additional twofold (97\% inhibition), thereby increasing the sensitivity of the vector (Simons et al. 1987). Some strong promoters can only be cloned if a transcriptional terminator is present downstream (Brosius 1984; Gentz et al. 1981); therefore, a single T1 terminator was placed at the $3^{\prime}$ end of the cassette.

The first set of promoter-probe vectors contains the broadhost-range pVS1 replicon and either a gentamicin or kanamycin resistance gene (Fig. 1A). These vectors also contain the p15a origin of replication from pACYC184 (ori) (Fig. 1A). The presence of four NotI sites in the pVS1 replicon made a simple insertion of the NotI-ended promoter-probe cassette difficult. Therefore, the $\mathrm{Km}^{\mathrm{r}}$ and $\mathrm{Gm}^{\mathrm{r}}$ vectors were constructed as follows. The $\mathrm{Km}^{\mathrm{r}}$ vectors were constructed by first changing the unique EcoRI site in the cat gene of the pVS1-derived plasmid pVSP6 to a NotI-compatible Bsp120I site. Insertion of the promoter-probe cassettes into this Bsp120I site created the vectors
pPROBE-KT, -KI, -KT', and -KI'. The $\mathrm{Gm}^{\mathrm{r}}$ vectors were constructed by first exchanging the $\mathrm{Tc}^{\mathrm{r}}$ gene of pACYC184 with the aacCl $\mathrm{Gm}^{\mathrm{r}}$ gene (described below) from the transposon $\mathrm{Tn} 5$ B22 (Simon et al. 1989). Next, the unique EcoRI site in the cat gene was changed to a NotI site. Finally, the promoter-probe cassettes were ligated into the NotI site and a BamHI-ended restriction fragment containing the pVS1 replicon was inserted into a unique $B c l$ site on the vector to create the plasmids pPROBE-GT, -GI, -GT', and -GI'.

Although the $\mathrm{Gm}^{\mathrm{r}}$ and $\mathrm{Km}^{\mathrm{r}}$ plasmids were stable without antibiotic selection and exhibited low background levels of expression in multiple taxa, we felt that a larger repertoire of antibiotic resistance was important in order to increase the versatility of this set of promoter-probe plasmids. Recently, a set of broadhost-range cloning vectors derived from the Bordetella bronchiseptica plasmid pBBR1 (Antoine and Locht 1992) was described (Kovach et al. 1994, 1995). These plasmids, pBBR1MCS, pBBR1MCS-2, pBBR1MCS-3, pBBR1MCS-4, and $\mathrm{pBBR} 1 \mathrm{MCS}-5$, contain a lacZ $\alpha$ fragment from $\mathrm{pBluescript}$ II-KS and confer resistance to $\mathrm{Cm}, \mathrm{Km}$, Tc, Ap, and $\mathrm{Gm}$, respectively. Plasmids containing the pBBR1 replicon are compatible with broad-host-range IncP, IncW, and IncQ group plasmids (Antoine and Locht 1992). Additionally, these plasmids have been shown to be highly stable and replicate in multiple, diverse species (Kovach et al. 1995). We first removed the pBluescript MCS in pBBR1MCS-2 and pBBR1MCS-4 and replaced it with a $B s p 120 \mathrm{I}$ linker, creating the plasmids pKSB2 and pKSB4, respectively. The four promoter-probe cassettes were inserted into $\mathrm{pKSB} 2$ to create the plasmids pPROBE-NT, NI, -NT', and -NI' (Fig. 1B). Similarly, plasmids pPROBE-AT, $\mathrm{AI}$, $-\mathrm{AT}^{\prime}$, and $\mathrm{AI}^{\prime}$ (Fig. 1B) were constructed by inserting the promoter-probe cassettes into pKSB4. We found the tetracycline resistance gene in pBBR1MCS-3 to be unsuitable, due to the

Table 1. Characteristics of the promoter-probe vectors

\begin{tabular}{|c|c|c|c|c|c|c|c|c|c|c|c|c|c|c|}
\hline \multirow[b]{2}{*}{ Plasmid } & \multirow[b]{2}{*}{ Resistance } & \multirow[b]{2}{*}{ Replicon } & \multirow[b]{2}{*}{ Reporter } & \multirow[b]{2}{*}{ Multicloning site } & \multicolumn{10}{|c|}{ Unique restriction sites $^{a}$} \\
\hline & & & & & B & $\mathbf{E}$ & $\mathbf{H}$ & $\mathbf{K}$ & $\mathbf{P}$ & Sc & $\mathbf{S a}$ & Sm & St & $\mathbf{X}$ \\
\hline pPROBE-GT & $\mathrm{Gm}^{\mathrm{r}}$ & $\mathrm{pVS} 1 / \mathrm{p} 15 \mathrm{a}$ & $g f p$ & $H i n \mathrm{dIII} \rightarrow E c o \mathrm{RI}$ & $X$ & $\mathrm{X}$ & $\mathrm{X}$ & $\mathrm{X}$ & $\mathrm{X}$ & $\mathrm{X}$ & $X$ & $\mathrm{X}$ & & \\
\hline pPROBE-GT' & $\mathrm{Gm}^{\mathrm{r}}$ & $\mathrm{pVS} 1 / \mathrm{p} 15 \mathrm{a}$ & $g f p$ & EcoRI $\rightarrow$ HindIII & $\mathrm{X}$ & $\mathrm{X}$ & $\mathrm{X}$ & $\mathrm{X}$ & $X$ & $\mathrm{X}$ & $X$ & $X$ & $X$ & \\
\hline pPROBE-GI & $\mathrm{Gm}^{\mathrm{r}}$ & $\mathrm{pVS} 1 / \mathrm{p} 15 \mathrm{a}$ & inaZ & $H i n \mathrm{dIII} \rightarrow E c o \mathrm{RI}$ & $X$ & $\mathrm{X}$ & $\mathrm{X}$ & & $\mathrm{X}$ & & & $\mathrm{X}$ & & \\
\hline pPROBE-GI' & $\mathrm{Gm}^{\mathrm{r}}$ & $\mathrm{pVS} 1 / \mathrm{p} 15 \mathrm{a}$ & inaZ & EcoRI $\rightarrow$ HindIII & $X$ & $\mathrm{X}$ & $\mathrm{X}$ & & $X$ & & & $X$ & $X$ & \\
\hline pPROBE-KT & $\mathrm{Km}^{\mathrm{r}}$ & $\mathrm{pVS} 1 / \mathrm{p} 15 \mathrm{a}$ & $g f p$ & $H i n \mathrm{dIII} \rightarrow E c o \mathrm{RI}$ & $X$ & $\mathrm{X}$ & $\mathrm{X}$ & $\mathrm{X}$ & & $\mathrm{X}$ & & & & \\
\hline pPROBE-KT' & $\mathrm{Km}^{\mathrm{r}}$ & $\mathrm{pVS} 1 / \mathrm{p} 15 \mathrm{a}$ & $g f p$ & EcoRI $\rightarrow$ HindIII & $\mathrm{X}$ & $\mathrm{X}$ & $\mathrm{X}$ & $\mathrm{X}$ & & $\mathrm{X}$ & & & $\mathrm{X}$ & \\
\hline pPROBE-KI & $\mathrm{Km}^{\mathrm{r}}$ & $\mathrm{pVS} 1 / \mathrm{p} 15 \mathrm{a}$ & inaZ & $H i n \mathrm{dIII} \rightarrow E c o \mathrm{RI}$ & $X$ & $\mathrm{X}$ & $\mathrm{X}$ & & & & & & & \\
\hline pPROBE-KI' & $\mathrm{Km}^{\mathrm{r}}$ & $\mathrm{pVS} 1 / \mathrm{p} 15 \mathrm{a}$ & inaZ & EcoRI $\rightarrow$ HindIII & $\mathrm{X}$ & $\mathrm{X}$ & $\mathrm{X}$ & & & & & & $\mathrm{X}$ & \\
\hline pPROBE-NT & $\mathrm{Km}^{\mathrm{r}}$ & pBBR1 & $g f p$ & $H i n \mathrm{dIII} \rightarrow E c o \mathrm{RI}$ & $\mathrm{X}$ & $\mathrm{X}$ & $\mathrm{X}$ & $X$ & & $\mathrm{X}$ & $X$ & $\mathrm{X}$ & & $X$ \\
\hline pPROBE-NT' & $\mathrm{Km}^{\mathrm{r}}$ & pBBR1 & $g f p$ & EcoRI $\rightarrow$ HindIII & $X$ & $\mathrm{X}$ & $\mathrm{X}$ & $\mathrm{X}$ & & $\mathrm{X}$ & $X$ & $\mathrm{X}$ & $\mathrm{X}$ & \\
\hline pPROBE-NI & $\mathrm{Km}^{\mathrm{r}}$ & pBBR1 & inaZ & $H i n \mathrm{dIII} \rightarrow E c o \mathrm{RI}$ & $X$ & $\mathrm{X}$ & $\mathrm{X}$ & & & & & $X$ & & $\mathrm{X}$ \\
\hline pPROBE-NI' & $\mathrm{Km}^{\mathrm{r}}$ & pBBR1 & inaZ & EcoRI $\rightarrow$ HindIII & $\mathrm{X}$ & $\mathrm{X}$ & $\mathrm{X}$ & & & & & $\mathrm{X}$ & $\mathrm{X}$ & \\
\hline pPROBE-AT & $A p^{r}$ & pBBR1 & $g f p$ & $H i n \mathrm{dIII} \rightarrow E c o \mathrm{RI}$ & $X$ & $\mathrm{X}$ & $\mathrm{X}$ & $\mathrm{X}$ & $\mathrm{X}$ & $\mathrm{X}$ & $X$ & $X$ & & $\mathrm{X}$ \\
\hline pPROBE-AT' & $\mathrm{Ap}^{\mathrm{r}}$ & pBBR1 & $g f p$ & EcoRI $\rightarrow$ HindIII & $X$ & $\mathrm{X}$ & $\mathrm{X}$ & $X$ & $X$ & $\mathrm{X}$ & $X$ & $\mathrm{X}$ & $\mathrm{X}$ & \\
\hline pPROBE-AI & $\mathrm{Ap}^{\mathrm{r}}$ & pBBR1 & inaZ & $H i n \mathrm{dIII} \rightarrow E c o \mathrm{RI}$ & $X$ & $\mathrm{X}$ & $\mathrm{X}$ & & $X$ & & & $\mathrm{X}$ & & $\mathrm{X}$ \\
\hline pPROBE-AI' & $\mathrm{Ap}^{\mathrm{r}}$ & pBBR1 & inaZ & EcoRI $\rightarrow$ HindIII & $X$ & $\mathrm{X}$ & $\mathrm{X}$ & & $\mathrm{X}$ & & & $X$ & $X$ & \\
\hline pPROBE-TT & $\mathrm{Tc}^{\mathrm{r}}$ & pBBR1 & $g f p$ & $H i n \mathrm{dIII} \rightarrow E c o \mathrm{RI}$ & $\mathrm{X}$ & $\mathrm{X}$ & $\mathrm{X}$ & $\mathrm{X}$ & & $\mathrm{X}$ & $X$ & $\mathrm{X}$ & & $\mathrm{X}$ \\
\hline pPROBE-TT' & $\mathrm{Tc}^{\mathrm{r}}$ & pBBR1 & $g f p$ & EcoRI $\rightarrow$ HindIII & $X$ & $\mathrm{X}$ & $\mathrm{X}$ & $\mathrm{X}$ & & $\mathrm{X}$ & $X$ & $\mathrm{X}$ & $\mathrm{X}$ & \\
\hline pPROBE-TI & $\mathrm{Tc}^{\mathrm{r}}$ & pBBR1 & inaZ & HindIII $\rightarrow$ Eco RI & $X$ & $\mathrm{X}$ & $\mathrm{X}$ & & & & & X & & $\mathrm{X}$ \\
\hline pPROBE-TI' & $\mathrm{Tc}^{\mathrm{r}}$ & pBBR1 & inaZ & EcoRI $\rightarrow$ HindIII & $\mathrm{X}$ & $\mathrm{X}$ & $\mathrm{X}$ & & & & & $X$ & $\mathrm{X}$ & \\
\hline pPROBE-OT & $\mathrm{Sp}^{\mathrm{r}} / \mathrm{Sm}^{\mathrm{r}}$ & pBBR1 & $g f p$ & $H i n \mathrm{dIII} \rightarrow E c o \mathrm{RI}$ & $X$ & $\mathrm{X}$ & $\mathrm{X}$ & $\mathrm{X}$ & $X$ & $\mathrm{X}$ & $X$ & $\mathrm{X}$ & & $\mathrm{X}$ \\
\hline pPROBE-OT' $^{\prime}$ & $\mathrm{Sp}^{\mathrm{r}} / \mathrm{Sm}^{\mathrm{r}}$ & pBBR1 & $g f p$ & EcoRI $\rightarrow$ HindIII & $X$ & $\mathrm{X}$ & $\mathrm{X}$ & $\mathrm{X}$ & $\mathrm{X}$ & $\mathrm{X}$ & $\mathrm{X}$ & $\mathrm{X}$ & $\mathrm{X}$ & \\
\hline pPROBE-OI & $\mathrm{Sp}^{\mathrm{r}} / \mathrm{Sm}^{\mathrm{r}}$ & pBBR1 & inaZ & $H i n \mathrm{dIII} \rightarrow E c o \mathrm{RI}$ & $\mathrm{X}$ & $\mathrm{X}$ & $\mathrm{X}$ & & $X$ & & & $X$ & & $\mathrm{X}$ \\
\hline pPROBE-OI' & $\mathrm{Sp}^{\mathrm{r}} / \mathrm{Sm}^{\mathrm{r}}$ & pBBR1 & $\operatorname{inaZ}$ & EcoRI $\rightarrow$ HindIII & $X$ & $\mathrm{X}$ & $\mathrm{X}$ & & $X$ & & & $\mathrm{X}$ & $\mathrm{X}$ & \\
\hline
\end{tabular}

\footnotetext{
${ }^{a}$ Restriction enzymes: $\mathrm{B}=$ BamHI, E $=$ EcoRI, H = HindIII, K = KpnI, P = PstI, Sa = SalI, Sc $=$ SacI, Sm =SmaI, St $=$ StuI, and X = XbaI .
} 
large number of sites for commonly used restriction enzymes (e.g., EcoRI, BamHI, and HindIII) that were present in the coding region. The $\mathrm{Tc}^{\mathrm{r}}$ gene in pWTT2081 (van der Bij et al. 1996) does not contain the restriction sites listed above; therefore, in order to construct a $\mathrm{Tc}^{\mathrm{r}}$ set of vectors, we first substituted the $\mathrm{Km}^{\mathrm{r}}$ gene in pKSB2 with the $\mathrm{Tc}^{\mathrm{r}}$ gene from pWTT2081. Insertion of the promoter-probe cassettes into the unique Bsp120I site of the $\mathrm{Tc}^{\mathrm{r}}$ version of pKSB2 created the plasmids pPROBE-TT, -TI, -TT', and -TI' (Fig. 1B). Finally, another set of promoterprobe plasmids was constructed by replacing the $\mathrm{Km}^{\mathrm{r}}$ gene in pKSB2 with the omega fragment, which confers resistance to spectinomycin and streptomycin (Prentski and Krisch 1984), and inserting the promoter-probe cassettes, creating the vectors pPROBE-OT, -OI, -OT', and -OI' (Fig. 1B).

\section{Construction of $\boldsymbol{g} \boldsymbol{f} \boldsymbol{p}$ half-life variant plasmids.}

Wild-type Gfp is an extremely stable protein: cells containing this protein show no decrease in fluorescence over at least $24 \mathrm{~h}$ (Andersen et al. 1998), a half-life that extends, essentially, over many bacterial generations. Although this stability can be an advantage at times, the long half-life of Gfp can complicate studies of gene regulation in which $g f p$ expression decreases over time or under various environmental conditions. Recently, unstable $g f p$ variants have been described (Andersen et al. 1998); addition of an AANDENYALAA tag to the C-terminal end of wild-type Gfp reduced the half-life of the protein to approximately $40 \mathrm{~min}$ in $E$. coli (Andersen et al. 1998). By altering the final three codons on this tag, Andersen et al. (1998) constructed three different alleles, Gfp[LVA],
Gfp[AAV], and Gfp[ASV] with half-lives of approximately 40,60 , and $110 \mathrm{~min}$, respectively. In order to incorporate these tagged $g f p$ alleles into our set of promoter-probe vectors, we replaced the HpaI-NsiI fragment from pPROBE-NT and pPROBE-NT' that contains the C-terminal portion of $g f p$ and the $r r n B 1$ T1 terminator with a HpaI-NotI fragment from the plasmids pJBA28 (wild-type Gfp), pJBA116 (Gfp[LVA]), pJBA118 (Gfp[AAV]), and pJBA120 (Gfp[ASV]) (Andersen et al. 1998). These half-life variant plasmids were designated pPROBE- $g f p$ [tagless], $-g f p[\mathrm{LVA}],-g f p[\mathrm{AAV}]$, and $-g f p[\mathrm{ASV}]$ and pPROBE'-gfp[tagless], - $g f p[\mathrm{LVA}],-g f p[\mathrm{AAV}]$, and $g f p[\mathrm{ASV}]$, respectively (Fig. 2).

Sensitivity and stability of the promoter-probe vectors.

It is very important for promoter-probe vectors to have as low a basal level of expression as possible in order to detect promoters of weak to moderate strength. The level of reporter gene activity in the absence of a promoter should be as close as possible to the activity of a strain without the plasmid. In order to quantify the background level of $g f p$ and inaZ expression in the set of plasmids described above, we transformed different pPROBE constructs into the following four strains: E. coli DH5 $\alpha$, Erwinia herbicola 299R, Pseudomonas syringae pv. syringae $\mathrm{B} 728 \mathrm{a}$, and $P$. syringae cit7del1. The fluorescence of cells transformed with pPROBE-GT did not differ from the fluorescence of untransformed strains (Table 2). Likewise, strains transformed with inaZ promoter-probe plasmids pPROBE-GI or pPROBE-KI had very low levels of ice nucleation, comparable to plasmidless strains (Table 2). The

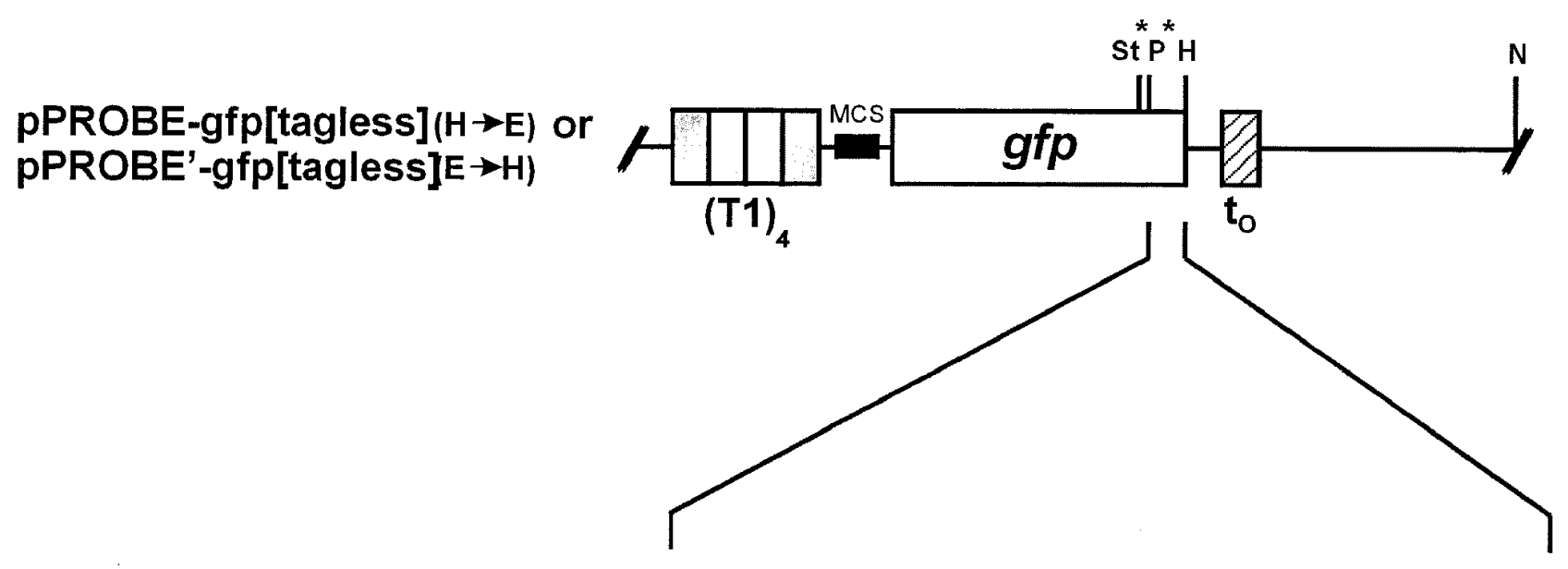

$\begin{array}{ll}\text { pPROBE-gfp[LVA] } & (H \rightarrow E) \text { or } \\ \text { pPROBE'-gfp[LVA] } & (E \rightarrow H) \\ \text { pPROBE-gfp[AAV] } & (H \rightarrow E) \text { or } \\ \text { pPROBE'-gfp[AAV] } & (E \rightarrow H) \\ \text { pPROBE-gfp[ASV] } & (H \rightarrow E) \text { or } \\ \text { pPROBE'-gfp[ASV] } & (E \rightarrow H)\end{array}$

CTGCAGCAAACGACGAAAACTACGCTTTAGTAGCTTAATAAGCTT

$\begin{array}{lllllllllll}A & A & N & D & E & N & Y & A & \text { L } & \text { V } & \text { A }\end{array}$

CTGCAGCAAACGACGAAAACTACGCTGCAGCAGTTTAATAAGCTT

CTGCAGCAAACGACGAAAACTACGCTGCATCAGTTTAATAAGCTT

$\begin{array}{lllllllllll}A & A & N & D & E & N & Y & A & A & S & V\end{array}$

Fig. 2. $g f p$ half-life variants of pPROBE-NT and pPROBE-NT'. The structures of the half-life-variant promoter-probe cassettes are shown (not drawn to scale). pPROBE- $g f p$ [tagless] and pPROBE'-g $f p$ [tagless] were derived from pPROBE-NT and pPROBE-NT', respectively, and contain wild-type $g f p$ alleles. Plasmids pPROBE- $g f p[\mathrm{LVA}],-g f p[\mathrm{AAV}]$, and - $g f p[\mathrm{ASV}]$ were derived from pPROBE-NT. Plasmids pPROBE'-gfp[LVA], -gfp[AAV], and - $g f p[\mathrm{ASV}]$ were derived from pPROBE-NT'. The $S t u \mathrm{I}$ and $P s t \mathrm{I}$ restriction sites are present in all but the [tagless] plasmid variants. $(\mathrm{H} \rightarrow \mathrm{E})$ and $(\mathrm{E} \rightarrow \mathrm{H})$ represent the orientation of restriction sites in the polylinker (Table 1; Fig. 1C). (T1) ${ }_{4}=$ four tandem T1 terminators from the Escherichia coli rrnB1 operon, $\mathrm{t}_{\mathrm{o}}=$ phage lambda $\mathrm{t}_{\mathrm{o}}$ terminator, $\mathrm{H}=$ HindIII, $\mathrm{N}=$ Not $\mathrm{I}, \mathrm{St}=$ StuI, and $\mathrm{P}=$ Pst $\mathrm{I}$. 
moderate level of ice nucleation in strain B728a(pPROBE-GI) reflects the native ice nucleating ability of wild-type strain B728A. To verify that these vectors would detect transcriptional signals, a 131-base pair (bp) HindIII-BamHI fragment, containing the nptII promoter (kan) from $\mathrm{Tn} 5$, was cloned into the MCS of pPROBE-GT, pPROBE-GI, and pPROBE-KI, creating pPROBE-GIkan, pPROBE-GIkan, and pPROBEKIkan, respectively. Cells transformed with these kan-gfp or kan-inaZ fusions showed a large increase in either fluorescence or ice nucleation (Table 2), indicating that these promoter-probe plasmids are suitable for the construction of transcriptional fusions. The Gfp data suggest that a promoter approximately 35-fold weaker than the moderately strong nptII promoter would give a fluorescence signal that approaches the limit of detection; conversely, anything stronger than that should give a signal well above background. InaZ, on the other hand, is a much more sensitive reporter, which allows detection of even weaker promoters; in E. herbicola $299 \mathrm{R}$, for example, the number of ice nuclei per cell is almost $10^{7}$ times higher with pPROBE-GIkan than with pPROBE-GI (Table 2). Due to the log-linear relationship between the amount of InaZ protein and the signal it generates (Lindgren et al. 1989), this translates into a more than 3,000-fold higher abundance of InaZ per cell. This then suggests that even a very weak promoter with a 3,000-fold lower transcriptional activity than $n p t I I$ gives a signal well above background level.

For measurements of gene expression in vitro, where antibiotic selection can be maintained over the time course of an experiment, plasmid stability is not a factor. However, in many cases, antibiotics cannot be applied in situ and plasmids must be maintained in the absence of selection. To quantify the stability of the pVS1 and pBBR1 plasmids, we transformed 299R with either pPROBE-GT, pPROBE-GI, or pPROBE-NT and grew the resulting transconjugants in LuriaBertani (LB) broth without selection for several generations. No plasmid loss was detected after 56 generations in either 299R(pPROBE-GT) or 299R(pPROBE-GI), or after 34 generations in 299R(pPROBE-NT) (data not shown). Hallmann et al. found similar results using pPROBE-GT transconjugants of Rhizobium etli grown for more than 80 generations without selection (J. Hallmann, A. Quadt-Hallmann, W. G. Miller, and
S. E. Lindow, unpublished data). Additionally, in experiments with 299R(pPROBE-GTkan), after 34 generations without selection, $>99 \%$ of the colonies remained fluorescent. A 100,000 -fold increase in cell number represents approximately 16 to 17 bacterial generations; therefore, the stability of these plasmids over more than 30 generations without selection far exceeds the requirements for most experiments in situ.

In some strains, especially those that contain a wild-type recA allele, recombination events may occur between the T1 terminators. This would involve either recombination between the four tandem upstream terminators, resulting in a decrease or increase in the number of upstream terminators, or recombination between the upstream terminators and the single downstream terminator, resulting in loss of the promoterprobe cassette. Recombination among the upstream terminators would only result, at worst, in a slight increase in basal reporter gene activity, because even one upstream terminator can reduce the background level of expression by $94 \%$. Cells in which recombination between the upstream terminators and the single downstream terminator has occurred are enriched only when the reporter gene product is overexpressed to levels that are lethal to the cell (e.g., with an extremely strong promoter). Therefore, we strongly suggest that recombination events be assessed in each strain for each fusion before quantifying reporter gene activity.

\section{Conclusions.}

This report describes the construction of a set of 24 highly stable, broad-host-range promoter-probe vectors. These plasmids use either $g f p$ or inaZ as the reporter gene. The construction of transcriptional fusions in these vectors is facilitated by the presence of two different MCSs, each containing numerous unique restriction sites. The presence of four terminators positioned upstream of the MCS confers a low basal level of reporter gene expression, thus enabling the detection of promoters of weak to moderate strength. In addition, this set of promoter-probe vectors contains five different antibiotic resistance genes; therefore, these vectors can be used in taxa with native antibiotic resistance (provided that the strain in question is not resistant to all five antibiotics) or in experiments involving two or more plasmids. Finally, a subset of

Table 2. Expression of $g f p$ and inaZ from different promoter-probe vectors in different hosts

\begin{tabular}{|c|c|c|c|c|}
\hline \multirow[b]{2}{*}{ Strain } & \multicolumn{2}{|c|}{$g f p$ expression } & \multicolumn{2}{|c|}{ inaZ $\mathrm{Z}$ expression } \\
\hline & Plasmid $^{\mathrm{a}}$ & Fluorescence $^{\mathrm{b}}$ & Plasmid $^{\mathrm{a}}$ & Ice nucleation activity ${ }^{b}$ \\
\hline \multirow[t]{3}{*}{ Escherichia coli $\mathrm{DH} 5 \alpha$} & None & 6.0 & n.a. ${ }^{c}$ & n.a. \\
\hline & pPROBE-GT & 6.9 & n.a. & n.a. \\
\hline & pPROBE-GTkan & 294 & n.a. & n.a. \\
\hline \multirow[t]{3}{*}{ Erwinia herbicola 299R } & None & 6.6 & None & $<8.24$ \\
\hline & pPROBE-GT & 6.6 & pPROBE-GI & $<8.07$ \\
\hline & pPROBE-GTkan & 338 & pPROBE-GIkan & -1.08 \\
\hline \multirow[t]{3}{*}{ Pseudomonas syringae $\mathrm{B} 728 \mathrm{a}$} & None & 6.7 & None & -4.24 \\
\hline & pPROBE-GT & 6.9 & pPROBE-GI & -3.98 \\
\hline & pPROBE-GTkan & 243 & pPROBE-GIkan & -0.89 \\
\hline \multirow[t]{3}{*}{ Pseudomonas syringae cit7del1 } & n.a. & n.a. & None & $<9.53$ \\
\hline & n.a. & n.a. & pPROBE-KI & -8.14 \\
\hline & n.a. & n.a. & pPROBE-KIkan & -3.29 \\
\hline
\end{tabular}

a Plasmids pPROBE-GTkan, pPROBE-GIkan, and pPROBEKIkan contain a 131-base pair $n p t I I$ promoter fragment from Tn5 fused to $g f p$ (pPROBEGTkan) or inaZ (pPROBE-GIkan and -KIkan).

${ }^{\mathrm{b}}$ Enzyme assays were performed as described in Materials and Methods. Fluorescence is expressed in arbitrary units normalized for $10^{9}$ cells. InaZ activity is expressed as $\log [$ ice nuclei per cell]. Each value is the mean of three replicate samples.

${ }^{c}$ n.a. $=$ Not applicable. 
plasmids has been constructed in which the wild-type $g f p$ allele in two of the vectors described above (i.e., pPROBE-NT and pPROBE-NT') has been replaced with unstable $g f p$ variants allowing real-time studies of gene regulation in situ.

\section{Nucleotide sequence accession numbers.}

As a representative subset of the pBBR1-based vector suite, we have deposited in GenBank the complete nucleotide sequences of all 12 pBBR1-derived vectors conferring resistance to kanamycin. Accession numbers are as follows: pPROBE-NT, AF286453; pPROBE-NT', AF286454; pPROBE-NI, AF286451; pPROBE-NI', AF286452; pPROBE- $g f p$ [tagless], AF286455; pPROBE'-gfp[tagless], AF286456; pPROBE- $g f p$ [LVA], AF286461; pPROBE'-gf $p$ [LVA], AF286462; pPROBE- $g f p$ [AAV], AF286457; pPROBE'-gfp[AAV], AF286458; pPROBE-gfp[ASV], AF286459; and pPROBE'-gfp[ASV], AF286460. The nucleotide sequences of all other pBBR1-derived plasmids (with the exception of those conferring resistance to tetracycline: the pWTT2081 Tc ${ }^{r}$ locus has not been sequenced) can be readily compiled using the above sequences, the cloning steps described in detail below, and the available sequence data for pBBR1MCS-2 (U23751), pBBR1MCS-4 (U25060), and the omega fragment (M60473). Unfortunately, the pVS1-based plasmids could not be considered for submission due to segments with unknown DNA sequences.

\section{MATERIALS AND METHODS}

Media, strains, growth conditions, and chemicals.

Bacterial strains were grown either on LB agar or in LB broth. E. coli $\mathrm{DH} 5 \alpha$ was grown at $37^{\circ} \mathrm{C}$, whereas Erwinia herbicola 299R (Brandl and Lindow 1996), P. syringae pv. syringae $\mathrm{B} 728 \mathrm{a}$ (Loper and Lindow 1987), and P. syringae cit7del1 (Lindow 1985) were grown at $24^{\circ} \mathrm{C}$. When used, gentamicin $(\mathrm{Gm})$, kanamycin $(\mathrm{Km})$, ampicillin (Ap), tetracycline $(\mathrm{Tc})$, spectinomycin $(\mathrm{Sp})$, streptomycin $(\mathrm{Sm})$, and rifampicin (Rf) were added at final concentrations of 15, 50, 150, $15,100,100$, and $100 \mu \mathrm{g} / \mathrm{ml}$, respectively. Restriction and DNA-modifying enzymes were purchased from New England Biolabs (Beverly, MA, U.S.A.) or Roche Molecular Biochemicals (Indianapolis, IN, U.S.A.). All chemicals were purchased from Sigma-Aldrich (St. Louis, MO, U.S.A.). All oligonucleotides were synthesized by Oligos, Etc. (Wilsonville, OR, U.S.A.).

\section{Construction of the promoter-probe cassettes.}

The $g f p$ and inaZ promoter-probe cassettes were constructed in three steps. First, $g f p$ and inaZ were amplified from pGreenTIR (Miller and Lindow 1997) and pUC1813ice (W. G. Miller, M. T. Brandl, B. Quiñones, and S. E. Lindow, unpublished data), respectively, and fused to a single $r r n B 1$ T1 terminator (Brosius et al. 1981) through a polymerase chain reaction (PCR) overlap extension method (Horton et al. 1990). $g f p$ was amplified using oligos T14GFP5' (5' ATTCCCTAACTAATAATGATTAACTTTATAAGGAGGAAAAAC 3'; ribosome-binding site underlined) and T1GFP3' (5' GATGCCTGGAATTAATTCCTATTTGTATAGTTCATCC 3'), and inaZ with oligos T14ICE5' (5' ATTCCCTAACTAATAACCCCAAAGGATCTATGAGGATGC 3'; putative ribosomebinding site underlined) and T1ICE3' (5' GATGCCTGGAATTGCGGGCTACTTTACCTCTATCCAGTC 3'). The T1 ter- minator was amplified from pRS1197 (W. G. Miller, unpublished data) using oligos T1NOT3' (5' CCGCGGCCGCCCCCAATTCCTGGCAGTTTATGG 3') and either T1GFP5' (5' CAAATAGAATTAATTCCAGGCATCAAATAAAAGAAAG GC 3') or T1ICE5' (5' GTAAATAGCCGCATTCCGGCCAAATAAACGAAAGGC $3^{\prime}$ ). All four PCR reactions were carried out for 30 cycles of $1 \mathrm{~min}$ at $95^{\circ} \mathrm{C}, 2 \mathrm{~min}$ at $50^{\circ} \mathrm{C}$, and $3 \mathrm{~min}$ at $72^{\circ} \mathrm{C}$. A sample of the amplified product from the $g f p$ and T1 (using oligo T1GFP5') reactions were added to a second PCR reaction containing oligos T1NOT3' and T14GFP5'. Likewise, a sample of the amplified product from the inaZ and T1 reactions (using oligo T1ICE5') was added to a second PCR reaction containing oligos T1NOT3' and T14ICE5'. Both PCR reactions were carried out for 30 cycles of $1.5 \mathrm{~min}$ at $95^{\circ} \mathrm{C}, 2 \mathrm{~min}$ at $50^{\circ} \mathrm{C}$, and $4 \mathrm{~min}$ at $72^{\circ} \mathrm{C}$. The amplified products were ligated into pCR2.1 (Invitrogen, Carlsbad, CA, U.S.A.) to generate a $5^{\prime} E c o$ RI site and create the plasmids pCR8 ( $g f p$ ) or pCR7 (inaZ).

Second, a plasmid containing four tandem copies of the T1 terminator fused to the pUC18 polylinker was constructed by first altering the plasmid pRS391 (Simons et al. 1987), which contains four $\mathrm{T} 1$ terminators flanked on the $5^{\prime}$ end by an EcoRI site and on the $3^{\prime}$ end by a BamHI site. In separate reactions, the EcoRI and BamHI sites were filled in with DNA polymerase (Klenow fragment) and ligated to an 8-bp NotI linker and a 10-bp HindIII linker (5' GGAAGCTTCC 3'), respectively. The resulting plasmid and pUC18 were then digested with HindIII and ScaI and ligated together to create the plasmid pNH18.

Finally, the NotI-ended promoter-probe cassettes were constructed by (i) digesting pNH18 with NotI and EcoRI, (ii) digesting pCR7 and pCR8 with EcoRI and NotI, and (iii) ligating the reporter gene fragments and the $\mathrm{T}_{(4)}$-MCS fragment into NotI digested pBluescript KS (Stratagene, La Jolla, CA, U.S.A.) to create the plasmids pNH18/8 ( $g f p)$ and pNH18/7 (inaZ). Both promoter-probe cassettes were verified by extensive restriction digest analysis and DNA sequencing. During the amplification of inaZ, a 15-bp deletion occurred: the sequence from the EcoRI site to the start codon is therefore $5^{\prime}$ GAATTCGGCTTAACCCCAAAGGATCTATGAGGATGCTGT AATG 3'.

\section{Construction of the promoter-probe vectors.}

To create a $\mathrm{Gm}^{\mathrm{r}}$ backbone for the promoter-probe vectors pPROBE-GT, -GI ,-GT', and -GI', pACYC184 was modified in several steps. First, the aacCl gene, which confers Gm resistance, was amplified from the transposon Tn5-B22 (Simon et al. 1989) using oligos Gm-5' (5' GGAATTCCCAATTTACCGAACAACTCCGC 3') and Gm-3' (5' GGAATTCCCAAACGATGCTCGCCTTCC $3^{\prime}$ ). PCR reactions were carried out for 30 cycles of $1 \mathrm{~min}$ at $95^{\circ} \mathrm{C}, 2 \mathrm{~min}$ at $50^{\circ} \mathrm{C}$, and $2 \mathrm{~min}$ at $72^{\circ} \mathrm{C}$. The amplified product was digested with EcoRI and ligated to EcoRI-digested pUC1813 (Kay and McPherson 1987) to create pUC1813Gm. pUC1813Gm was digested with EcoRI, filled in with DNA polymerase (Klenow fragment), and ligated to pACYC184, which had been digested with HincII and HindIII and filled in with DNA polymerase (Klenow fragment). This step essentially swapped the $\mathrm{Tc}^{\mathrm{r}}$ gene of pACYC184 with a $\mathrm{Gm}^{\mathrm{r}}$ gene. Next, the unique EcoRI site present in the $\mathrm{Cm}^{\mathrm{r}}$ gene was filled in and ligated to an 8bp NotI linker. The two NotI-ended promoter-probe cassettes 
were then ligated into this NotI site to create the plasmids pG7 (inaZ) and pG8 ( $g f p)$. Finally, the broad-host-range pVS1 replicon containing replication and stability functions was inserted into pG7 and pG8 by first ligating an approximately $7.8-\mathrm{kb}$ filled-in BamHI-SalI fragment from pWTT2081 (van der Bij et al. 1996) into SmaI-digested pUC1813 and then ligating a BamHI-ended pVS1 fragment into BclI-digested pG7 and pG8 to create pPROBE-GI and pPROBE-GT, respectively.

Additionally, two promoter-probe vectors (pPROBE-GT and $\left.-\mathrm{GI}^{\prime}\right)$ were created in which the order of the restriction sites in the MCS was reversed. Two linkers were synthesized so that, when annealed together, they would form a doublestranded-MCS adaptor with a 5' HindIII compatible end and a 3' EcoRI compatible end. Plasmids pPROBE-GT and pPROBEGI were digested with HindIII and EcoRI and ligated to the new MCS adaptor, creating pPROBE-GT' and pPROBE-GI', respectively. Insertion of the adaptor disrupted the original HindIII and EcoRI sites. The MCS adaptor does not contain $X b a \mathrm{I}$ or $S p h \mathrm{I}$ sites; also, in order to facilitate blunt-ended cloning in situations in which the SmaI site is not unique, a StuI site was added. This $S t u \mathrm{I}$ site is unique in pPROBE-GT', pPROBE-GI', and all subsequent promoter-probe constructs containing the reverse MCS.

In order to create the promoter-probe vectors pPROBE-KT, -KI, - $\mathrm{KT}^{\prime}$, and - $\mathrm{KI}^{\prime}$, the four NotI-ended promoter-probe cassettes were to be inserted into the $\mathrm{Cm}^{\mathrm{r}}, \mathrm{Km}^{\mathrm{r}}$ broad-host-range vector pVSP6 (obtained from William Tucker, DNA Plant Technologies, Oakland, CA, U.S.A.). The presence of four NotI sites in the pVS1 replicon of that plasmid made a simple ligation difficult. Therefore, a Bsp120I linker (5' AATTGGGGCCCC $3^{\prime}$ ) was synthesized and annealed to itself to form a double-stranded adaptor with EcoRI-compatible ends. This adaptor was then ligated into the unique EcoRI site present within the cat gene of pVSP6, disrupting this site in the process. This plasmid was digested with Bsp120I and ligated to the four NotI ended promoter-probe fragments to create pPROBE$\mathrm{KT}$, $-\mathrm{KI},-\mathrm{KT}^{\prime}$, and $-\mathrm{KI}^{\prime}$.

An additional set of promoter-probe vectors with a wider variety of antibiotic resistances was constructed by modifying the previously described pBBR1MCS series of broad-hostrange vectors (Kovach et al. 1995). The MCS in the plasmids pBBR1MCS-2 and pBBR1MCS-4 was replaced with a unique Bsp120I site by a procedure similar to that described above. Two oligos (5' GGGGCCCCGTAC 3' and 5' GGGGCCCCAGCT $3^{\prime}$ ) were synthesized and annealed to generate a doublestranded adaptor with KpnI- and SacI-compatible ends. pBBR1MCS-2 and pBBR1MCS-4 were digested with KpnI and $S a c I$ and ligated to the Bsp120I adaptor to create plasmids pKSB2 and pKSB4, respectively. The $\mathrm{Km}^{\mathrm{r}}$ gene in pKSB2 was replaced by either a $\mathrm{Tc}^{\mathrm{r}}$ gene or the omega fragment that confers Sp/Sm resistance (Prentki and Krisch 1984). This was accomplished by making use of the unique Bsp120I restriction site present on pBluescript KS and the unique BglII site present $3^{\prime}$ of the $\mathrm{Km}^{\mathrm{r}}$ gene on pKSB2. A HindIII-ended omega fragment from pUC1318O (E. Clark, unpublished data: constructed by inserting an approximately 2-kb HindIII-ended omega fragment [Prentki and Krisch 1984] into the HindIII site of pUC1318 [Kay and McPherson 1987]) was filled in with DNA polymerase (Klenow fragment) and ligated to HincII/SmaI-digested pBluescript KS. The resulting plasmid was digested with Bsp120I and BamHI and the approximately 2-kb Sp ${ }^{\mathrm{r}} / \mathrm{Sm}^{\mathrm{r}}$ fragment was ligated to $B s p 120 \mathrm{I} / B g l \mathrm{II}-$ digested $\mathrm{pKSB} 2$ to create the plasmid $\mathrm{pKSB} \Omega$. Similarly, an approximately 2.2-kb filled-in HindIII/SalI fragment from pWTT2081, which confers Tc resistance, was cloned into pKSB2 via pBluescript KS to create the plasmid pKSB2tet. Finally, the four NotI-ended promoter-probe cassettes were cloned into Bsp120I-digested plasmids $\mathrm{pKSB} 2, \mathrm{pKSB} 4, \mathrm{pKSB} \Omega$, and pKSB2tet to create the plasmids pPROBE-NT, -NI, -NT', $\mathrm{NI}^{\prime},-\mathrm{AT},-\mathrm{AI},-\mathrm{AT}^{\prime},-\mathrm{AI}^{\prime},-\mathrm{OT}$, -OI, -OT', -OI', -TT, -TI, -TT', and $-\mathrm{TI}^{\prime}$, respectively.

\section{$g f p$ half-life-variant plasmids.}

To construct the $g f p$ half-life variant plasmids, the HpaINotI fragment containing the C-terminal portion of $g f p$ and the bacteriophage lambda $\mathrm{t}_{0}$ terminator from plasmid pJBA28, pJBA116, pJBA118, or pJBA120 (Andersen et al. 1998) was first cloned into the plasmid $\mathrm{pCR} 2.1$. The $g f p$-terminator fragment was then excised from the pCR2.1 subclones with HpaI and PstI. Plasmids pPROBE-gfp[tagless], pPROBE$g f p[\mathrm{LVA}]$, pPROBE- $g f p[\mathrm{AAV}]$, and pPROBE- $g f p[\mathrm{ASV}]$ were constructed by replacing the $\mathrm{HpaI}-\mathrm{Nsi}$ fragment of pPROBE$\mathrm{NT}$, containing the C-terminal portion of $g f p$ and the $r r n B 1 \mathrm{~T} 1$ terminator, with the HpaI-PstI fragment. Plasmids pPROBE'$g f p$ [tagless], pPROBE'-gfp[LVA], pPROBE'-gfp[AAV], and pPROBE'-gfp[ASV] were constructed in a similar manner by replacing the HpaI-NsiI fragment of pPROBE-NT'.

\section{Plasmid transformation.}

Plasmid DNA was conjugated into Erwinia herbicola 299R and the $P$. syringae strains by triparental mating using $E$. coli strain DH5 $\alpha$ as the donor and either DH5 $\alpha$ (pRK2013) (Figurski and Helinski 1979) or DH5 $\alpha$ (pRK2073) (Better and Helinski 1983) as the helper.

\section{Enzyme assays.}

Cells from overnight LB cultures were centrifuged, washed once with $10 \mathrm{mM}$ phosphate buffer, and resuspended in phosphate buffer at a final concentration of approximately $2 \times 10^{9}$ cells per ml. Ice nucleation assays were performed as previously described (Lindow 1990) with cells that were grown at $28^{\circ} \mathrm{C}$. Cells containing the InaZ protein exhibit a maximum frequency of ice nucleation when cultures are grown in the temperature range of 18 to $24^{\circ} \mathrm{C}$ (Lindow 1995). Even though the ice nucleation frequency is reduced approximately 100fold when cells are grown at $28^{\circ} \mathrm{C}$ (Lindow 1995), the ice nucleation at that temperature is still well above background. Most strains of $E$. coli will grow at $28^{\circ} \mathrm{C}$; however, in this experiment, $\mathrm{DH} 5 \alpha$ did not grow well at this temperature. Therefore, ice nucleation assays were not performed for this strain. For the $g f p$ promoter-probe vectors, fluorescence was measured on a Perkin-Elmer LS50B Luminescence Spectrometer (Perkin Elmer Instruments, Norwalk, CT, U.S.A.) at an excitation wavelength of $490 \mathrm{~nm}$, an emission wavelength of 510 $\mathrm{nm}$, and emission/excitation slit widths of $8 \mathrm{~nm}$. Intensity readings are represented by arbitrary units and were normalized to a cell density of $10^{9}$ cells per ml.

\section{ACKNOWLEDGMENTS}

We thank Michael E. Kovach for sending the pBBR1 clones; Jens Bo Andersen from the Molin lab for plasmids pJBA28, pJBA116, pJBA118, 
and pJBA120; and William Tucker, DNA Plant Technologies (Oakland, CA, U.S.A.) for plasmids pWTT2081 and pVSP6. This work was supported in part by grant 96-35303 from the United States Department of Agriculture, grant DR-FG03-86ER13518 from the Department of Energy, and grant DEB-9615280 from the National Science Foundation.

\section{LITERATURE CITED}

Andersen, J. B., Sternberg, C., Poulsen, L. K., Bjørn, S. P., Givskov, M., and Molin, S. 1998. New unstable variants of green fluorescent protein for studies of transient gene expression in bacteria. Appl. Environ. Microbiol. 64:2240-2246.

Antoine, R., and Locht, C. 1992. Isolation and molecular characterization of a novel broad-host-range plasmid from Bordetella bronchiseptica with sequence similarities to plasmids from Gram-positive organisms. Mol. Microbiol. 6:1785-1799.

Better, M., and Helinski, D. R. 1983. Isolation and characterization of the recA gene of Rhizobium meliloti. J. Bacteriol. 155:311-316.

Brandl, M. T., and Lindow, S. E. 1996. Cloning and characterization of a locus encoding an indolepyruvate decarboxylase involved in indole-3acetic acid synthesis in Erwinia herbicola. Appl. Environ. Microbiol. 62:4121-4128.

Brosius, J. 1984. Toxicity of an overproduced foreign gene product in Escherichia coli and its use in plasmid vectors for the selection of transcription terminators. Gene 27:161-172.

Brosius, J., Dull, T. J., Sleeter, D. D., and Noller, H. F. 1981. Gene organization and primary structure of a ribosomal rRNA operon from Escherichia coli. J. Mol. Biol. 147:107-127.

Casadaban, M. J., and Cohen, S. N. 1980. Analysis of gene control signals by DNA fusion and cloning in Escherichia coli. J. Mol. Biol. 138:179-207.

Diaz, E., and Garcia, J. L. 1990. Construction of a broad-host-range pneumococcal promoter-probe plasmid. Gene 90:163-167.

Figurski, D. H., and Helinski, D. R. 1979. Replication of an origincontaining derivative of plasmid RK2 dependent on a plasmid function provided in trans. Proc. Natl. Acad. Sci. U.S.A. 76:1648-1652.

Gentz, R., Langner, A., Chang, A. C. Y., Cohen, S. N., and Bujard, H. 1981. Cloning and analysis of strong promoters is made possible by the downstream placement of a RNA termination signal. Proc. Natl. Acad. Sci. USA 78:4936-4940.

Heeb, S., Itoh, Y., Nishijyo, T., Schnider, U., Keel, C., Wade, J., Walsh, U., O'Gara, F., and Haas, D. 2000. Small, stable shuttle vectors based on the minimal pVS1 replicon for use in Gram-negative, plantassociated bacteria. Mol. Plant-Microbe Interact. 13:232-237.

Hirsch, P. R., Wang, C. L., and Woodward, M. J. 1986. Construction of a $\mathrm{Tn} 5$ derivative determining resistance to gentamicin and spectinomycin using a fragment cloned from R1033. Gene 48:203-209.

Horton, R. M., Cai, Z. L., Ho, S. N., and Pease, L. R. 1990. Genesplicing by overlap extension: Tailor-made genes using the polymerase chain reaction. Biotechniques 8:528-535.

Kay, R., and McPherson, J. 1987. Hybrid pUC vectors for addition of new restriction enzyme sites to the end of DNA fragments. Nucleic Acids Res. 15:2778.

Konyecsni, W. M., and Deretic, V. 1988. Broad-host-range plasmid and M13 bacteriophage-derived vectors for promoter analysis in Escherichia coli and Pseudomonas aeruginosa. Gene 74:375-386.

Kovach, M. E., Elzer, P. H., Hill, D. S., Robertson, G. T., Farris, M. A., Roop, R. M., II, and Peterson, K. M. 1995. Four new derivatives of the broad-host-range cloning vector pBBR1MCS, carrying different antibiotic-resistance cassettes. Gene 166:175-176.

Kovach, M. E., Phillips, R. W., Elzer, P. H., Roop, R. M., II, and Peterson, K. M. 1994. pBBR1MCS: A broad-host-range cloning vector. BioTechniques 16:800-801.

Lindgren, P. B., Frederick, R., Govindarajan, A. G., Panopoulos, N. J., Staskawicz, B. J., and Lindow, S. E. 1989. An ice nucleation reporter gene system: Identification of inducible pathogenicity genes in Pseudomonas syringae pv. phaseolicola. EMBO J. 8:2990-3001.

Lindow, S. E. 1985. Ecology of Pseudomonas syringae relevant to the field use of Ice ${ }^{-}$deletion mutants constructed in vitro for plant frost control. Pages 23-25 in: Engineering Micro-Organisms in the Environment: Scientific Issues. Am. Soc. Microbiol. Washington, DC, U.S.A.

Lindow, S. E. 1990. Bacterial ice nucleation activity. Pages 185-198 in: Methods in Phyto-Bacteriology. S. Klement, K. Rudolf, and D. D. Sands, eds. Akadémiai Kiadó, Budapest.

Lindow, S. E. 1995. Membrane fluidity as a factor in production and stability of bacterial ice nuclei active at high subfreezing temperatures. Cryobiology 32:247-258.

Loper, J. E., and Lindow, S. E. 1987. Lack of evidence for in situ fluorescent pigment production by Pseudomonas syringae pv. syringae on bean leaf surfaces. Phytopathology 77:1449-1454.

Manoil, C., and Beckwith, J. 1985. TnphoA: A transposon probe for protein export signals. Proc. Natl. Acad. Sci. U.S.A. 82:8129-8133.

Miller, W. G., and Lindow, S. E. 1997. An improved GFP cloning cassette designed for prokaryotic transcriptional fusions. Gene 191:149-153.

Nikaido, H. E., and Vaara, M. 1985. Molecular basis of bacterial outer membrane permeability. Microbiol. Rev. 49:1-32.

Prentki, P., and Krisch, H. M. 1984. In vitro insertional mutagenesis with a selectable DNA fragment. Gene 29:303-313.

Ronald, S. L., Kropinski, A. M., and Farinha, M. A. 1990. Construction of broad-host-range vectors for the selection of divergent promoters. Gene 90:145-148.

Silhavy, T. J., and Beckwith, J. R. 1985. Uses of lac fusions for the study of biological problems. Microbiol. Rev. 49:398-418.

Simon, R., Quandt, J., and Klipp, W. 1989. New derivatives of transposon Tn 5 suitable for mobilization of replicons, generation of operon fusions and induction of genes in Gram-negative bacteria. Gene 80:161-169.

Simons, R. W., Houman, F., and Kleckner, N. 1987. Improved single and multicopy lac-based cloning vectors for protein and operon fusions. Gene 53:85-96.

van der Bij, A. J., de Weger, L. A., Tucker, W. T., and Lugtenberg, B. J. J. 1996. Plasmid stability in Pseudomonas fluorescens in the rhizosphere. Appl. Environ. Microbiol. 62:1076-1080. 